\title{
Innovations and Research and Development Spending in India's Manufacturing Sector: Growth Implications
}

\author{
Mohd. Aijaz*
}

\begin{abstract}
Indian manufacturing sector has been experiencing a sluggish growth since the last many years. The global manufacturing has undergone a paradigm shift in recent times relying on the growing network of supply chain. In the new manufacturing system, production is largely carried out through fragmentation-based vertical specialization. Research and Development $(R \& D)$ and consequent innovations determine the competitive strength in this highly fragmented production process. Statistics reveal that India spends a meagre proportion of GNP on $R \& D$. This paper examines the status and role of in-house industrial $R \& D$ and discusses how $R \& D$ spending can promote business innovations and entrepreneurship crucial for sustaining the growth of Indian manufacturing in the midst of changing world of manufacturing.
\end{abstract}

Keywords: Innovations, R\&D, Entrepreneurship, Vertical specialisation.

\subsection{Introduction}

The lacklustre performance of India's manufacturing industries witnessed during the last two decades has caused disquiet among policy makers and researchers. Data amply show that during 1990s, manufacturing GDP grew at a rate of $6.7 \%$ annually and around $8.7 \%$ during 2000s, and its share in India's GDP virtually remained constant in the range of 14-17\%. The relative size and pace of manufacturing sector is so important that it has become an engine of growth of many countries such as China, Korea, Taiwan, Japan, Germany to name a few. The impressive rise in GNP recorded during the last two decades is largely contributed by the robust growth of the services sector. But the services sector-led growth has neither been accompanied with sufficient employment generation, nor was consistent with the vast untapped reservoir of unskilled labour. In fact, there are very few countries in the world which have shown sustained economic growth of respectable magnitudes by just focusing on the services sector (Mani, 2011).

\footnotetext{
* Department of Statistics \& Operations Research, Aligarh Muslim University, Aligarh.
} (e-mail: ahzam1@yahoo.com) 
In contrast, manufactures are more tangible and tradable and hence more dependable. Economic theories and empirical studies have already proved positive relationship between R\&D expenditure, innovations, industrial change and growth. In the global market economy, ability of nations to create, absorb, and commercialize innovations determines their competitiveness (GoI, 2008). It is hypothesised that increased in-house $R \& D$ efforts and resultant industrial innovations could provide a sustainable solution to the stagnant growth of Indian manufacturing sector.

The world of manufacturing has witnessed a paradigm shift in recent times. In the new world of manufacturing it seems difficult for India to realize faster and inclusive growth target unless distortions in the manufacturing is sorted out. In fact there are a number of quality researches which have found probable causes of the dismal growth of manufacturing industries notably, as infrastructural bottleneck (Nagraj, 2011), labour market rigidities (Kochchar et al., 2006), financial constraints (Gupta et al. 2008; Bhattacharjee \& Chakarbarty, 2013), lack of R\&D expenditure (Mani, 2009). This paper attempts to analyse the role of industrial innovations in spurring manufacturing growth and how R\&D spending can influence the generation of in-house commercial innovations and entrepreneurship in the midst of changing world of manufacturing. The structure of the paper is composed of four sections. First section outlines the paradigm shift in the global manufacturing and explains why India failed to take advantage of growing fragmentation-based vertical specialization in manufacturing. In the next section current status and pattern of R\&D spending in India's industrial sector has been discussed. The third section examines positive connection between level of $R \& D$ spending and production engineering and shows how important countries of Asia have been able to grow their manufacturing at a faster pace. In the last section, conclusions based on author's observations, logical arguments of experts and statistical evidences with policy prescriptions are mentioned.

It is now appropriate to spell out the paradigm shift in the global manufacturing landscape. The world of manufacturing has undergone structural change with the application of IT-enabled inputs and reduction of tariff barriers. The 'scale' of operations has given place to growing networks of value chain as a source of competitiveness in many industries. The manufacturers are experiencing rapidly changing market characterized by shorter product life-cycle and proliferation of new product varieties. The producers have to engineer products quicker and cheaper in order to reap the competitive advantage. Enterprises are focussing on their core competence and outsourcing all other activities to specialized organizations which can deliver better and cheaper (GoI, 2008). There are certain products/sectors in India like auto-parts, pharmaceuticals, fine chemicals, IT manifesting considerable amount of capabilities 
required in global system. But India largely remained a minor player in global production networks and vertical specialization in manufacturing. Global production networks refer to the links between a lead or key firm and its supplies in different countries (Weiss, 2011). In certain industries (e.g. electronics and automobiles), technology makes it possible to sub-divide the production process into discrete stages. In such industries, fragmentation of production process into smaller and more specialized components allows firms to locate parts of the production in countries where intensively used resources are available at lower cost. A high level of fragmentation (vertical specialization) based production process occurs when countries specialize in particular stage of a production sequence rather than in the entire good, has been an important factor in driving the growth of East-Asian countries. This type of production process is the result of increasing inter-connected production processes that form a vertical chain across many countries with each specialising according to factor intensities involved at different stages in production. Since this strategy involves processing or assembly of imported parts and components, the net domestic value added per unit of exported good is generally not very high. However, since the scale of operations is usually very high, the total domestic value addition from these activities is considerably high, contributing to employment generation for a large number of migrant workers in China. Based on imported parts and components, China has emerged as a global hub for the final assembly activities in manufacturing (Veeramani, 2013). Unlike China, the surplus labour in India could not be transferred to modern sectors for employment in a large measure. China and other East-Asian countries have better positioned themselves with this type of high level of fragmentation (vertical specialization) based manufacturing with global production chains.

In contrast, India has been locked out of the vertically integrated global supply chains in manufacturing industries mainly because country's incentive structures are not in alignment with its comparative advantage in unskilled labour intensive activities (Veeramani, 2013). India is relatively skill and capital scarce country where about $33 \%$ of population with no or primary schooling (unskilled labour) is abundant in 2010. Nevertheless, India's manufacturing industries over the years followed relatively capital and skill-intensive path as evidenced from some important research work done by Kochchar et al (2006), Panagriya (2008) and Krueger (2010). The heavy reliance on import substitution and indiscriminate cheap industrial credit policy regime were cited as possible explanations. Desai (1982) concluded that India's inward looking technology and trade policies did hinder her pace of technological innovations. This strategy of industrialization proved costly, time consuming and counter-productive. Moreover, it was not in tune with true comparative advantage of India in labour intensive production. 
Mani (2011: 16) while highlighting the importance of manufacturing said, "But history has shown us that most countries in the developed world and even in developing world (such as Korea, China and group of countries referred to as Asian Tigers) have all had sustained economic growth by focusing more on the manufacturing sector where output is more tangible and where most of the innovations are first generated." The lack of dynamism in labour intensive manufacturing is a matter of concern because it holds the potential to absorb large pool of unskilled labour. Though recent success stories of autoparts, chemicals, pharmaceuticals and IT products are high skilled and capital intensive, yet the kind of growth dynamism they have demonstrated is an example for Indian manufacturing. Their voluminous production backed by $\mathrm{R} \& \mathrm{D}$ efforts and organizational flexibility enabled them to respond to volatile global market. Their notable growth proved that mastering ability to manufacture innovatively, quickly and efficiently is the real strength to face the challenges of competition in a situation of fragmentation-based vertical specialization.

\subsection{Status of Industrial R\&D and Entrepreneurship}

In the globalising market economy, the competitive strength of industrial sector in general and manufacturing in particular may greatly be influenced by the quantum and composition of the total investment made in the country's R\&D domain. The Gross Expenditure on Research and Development (GERD) to GDP ratio (R\&D intensity) and patents are the most important indicators of innovativeness of a country. There are three classes of industry-level determinants of R\&D intensity; demand, appropriability and technological opportunity conditions (Cohen and Levin, 1989). Acquisition of technological knowledge is a deliberate economic activity like any other investment. Besides, the in-house R\&D efforts, other sources of technological innovations are import of technology and knowhow from abroad as well as domestically. These sources operate as compliments or substitutes in the production of technological knowledge, and the firm maximises profits by choosing the degree to which it draws from each source (Raut, 1985). Assuming in-house R\&D activities as the only source of innovations, translation of R\&D investment to creation of novel processes/products or improvements in existing products is a highly uncertain and complex process for a firm. This is because of indivisibility, unobserveability, public good and non-linear characteristics associated with the production of knowledge. The existence of knowledge spillover encourages private economic agents to under invest in $R \& D$ (Mani, 2009). Therefore, the role of government in promoting investment in industrial $R \& D$ has increasingly been recognized even in market-oriented economies. A firm's R\&D satisfies two important 
functions; it not only generates new knowledge, but also contributes to the firm's absorptive capacity. Absorptive capacity is the ability of a firm to recognize the value of new, external information, assimilate it and apply it to commercial ends (Cohen and Levinthal, 1990). The entire innovation life-cycle from creation to commercial application is however very complex. Its conversion depends on the nature and size of enterprise, market structure, public policy and support for R\&D investment.

As indicated in Table-1, India's GERD as a proportion of GDP was a meagre $0.88 \%$ and out of which the share of industrial R\&D was $30.4 \%$ only. This is dismally low in comparison to industrially developed countries where it is above $2 \%$ and over 50 $\%$ respectively. Moreover, the R\&D expenditure as percentage of sales turnover for industrial sector taken together was $0.55 \%$ which was quite less in relation to their advertising expenditure of $1.56 \%$. Whereas this amount as percentage of sales volumes for a number of developed countries varies between 3\% and $4 \%$ (GoI, 2008). Data in Table-1 also reveals that almost stagnant GERD as GDP ratio is accompanied by a twofold increase in the industrial share from $14 \%$ in 1991 to over $30 \%$ in 2005-06. Table-2 shows that pharmaceuticals, transportation, chemicals and IT industries are the significant spenders on R\&D contributing more than $65 \%$ of the total industrial expenditure. Of late, these products/industries have achieved highest growth rate in manufacturing sector. It is pertinent to note that in the industrial sector, much of the R\&D was carried out by a few private sectors led by drugs and pharmaceuticals manufacturers. Private sector accounts for more than $80 \%$ of the total industrial R\&D investment in the country. For instant, $R \& D$ investments of private sector pharmaceuticals have been registering an increase of almost $35 \%$ per annum. In other words, in terms of $\mathrm{R} \& \mathrm{D}$ performance, the private sector enterprises are moving towards the core of India's innovation system (Mani, 2009). While defence, space and oil industries consumed the bulk of the government expenditure. Though the government accounts about $65 \%$ of the total R\&D performed in the country, the spill over of government research to civilian use is very limited in Indian context. On the other, the increase in the share of R\&D performed by business enterprises tends to implement the results of their research rather more quickly than the government sector where much of the research does not fructify into products and process for the country as a whole (Mani 2013). It may now be concluded that industrial sector $R \& D$ is concentrated in private sector pharmaceutical and fine chemical industries. The aforesaid statistical facts further reflect that country has a poor innovative culture to bring back buoyancy and dynamism much required in the major part of manufacturing industries.

India has no dearth of innovative and entrepreneurial ideas at the grass root level. But the process of translating the innovations into viable business enterprises where 
investment could be smaller and risk being higher is severely restricted. This is possibly why many successful business experiments do not reach scale due to inadequate training and mentoring. Socio-cultural reasons are also responsible for it. The genesis of innovation is human inventive traits shaped by culture.

Table 1: India's R\&D Expenditure/GDP ratio and Share of Industrial R\&D, 199091 to 2007-08

\begin{tabular}{|c|c|c|}
\hline Year & $\begin{array}{c}\text { GERD as ratio of } \\
\text { GDP }(\boldsymbol{\%})\end{array}$ & $\begin{array}{c}\text { Share of Industrial R\&D } \\
(\mathbf{\%})\end{array}$ \\
\hline $1990-91$ & 0.77 & 13.84 \\
\hline $1995-96$ & 0.69 & 21.74 \\
\hline $1998-99$ & 0.77 & 21.17 \\
\hline $1999-00$ & 0.81 & 18.46 \\
\hline $2000-01$ & 0.84 & 18.05 \\
\hline $2001-02$ & 0.81 & 19.33 \\
\hline $2002-03$ & 0.80 & 20.27 \\
\hline $2003-04$ & 0.78 & 20.05 \\
\hline $2004-05$ & 0.75 & 19.81 \\
\hline $2005-06$ & 0.88 & 30.40 \\
\hline$* 2007-08$ & 0.88 & 34.13 \\
\hline
\end{tabular}

Source: Department of Science \&Technology (GOI), different years.

GERD- Gross Expenditure on Research \&Development.

Table 2: Industry-wise Distribution of Total Industrial R\&D Expenditure in 2005-06

\begin{tabular}{|l|c|}
\hline \multicolumn{1}{|c|}{ Industry } & Share (\%) \\
\hline Drugs \& Pharmaceuticals & 37.36 \\
\hline Transportation/Engg. Industries & 18.39 \\
\hline Defense Industries & 6.89 \\
\hline Chemicals (other than fertilizers) & 6.16 \\
\hline Electricals \& Electronics & 5.68 \\
\hline Fuels & 4.32 \\
\hline Information Technology (IT) & 4.20 \\
\hline Bio-technology & 3.68 \\
\hline Metallurgical Industries & 3.06 \\
\hline Others & 8.43 \\
\hline & $\mathbf{1 0 0 . 0 0}$ \\
\hline
\end{tabular}

Source: Dept. of Science \&Technology, GoI, New Delhi, 2008. 
According to Indiresan (2004), technological innovations are embedded in culture. The pace of industrial innovations and their absorption is slow in culture where people are traditional in outlook and risk-averse. Given the prevailing social values, people seldom regard business entrepreneurship as an instrument of wealth creation. There is a strong preference to job, especially government jobs, for reasons of social security and sense of sharing state power. The fact that the best of India's engineering graduates do not work in industries is indicative of unfavourable environment. In other words, manufacturing has not been the attractive career option for talented youths (GoI, 2011). The Indian educational system has not adequately changed the mind set to inculcate values like strive to achieve, risk- prepared social behaviour, and scientific spirit essential to venture and run an enterprise. Further, R\&D is still a least-preferred vocational choice among the educated class. In India, there are 140 researchers per million population as against 461 in Brazil, 926 in China, and 5546 in Japan (GoI 2008). This reminds us to the declining trends of research in Indian universities which have met a limited success in industrial research and innovations. There is currently a shortage of science and engineering personnel required by the industries. It reflects that the higher education sector in India is not fulfilling science and technology needs of the manufacturing industry. However, the sector is an important source of human resource for the other actors in India's national system of innovations (Mani 2009). There is a vast potential of first-generation entrepreneurs in the country, yet they largely deter to enter into manufacturing business due to certain perceived barriers. Dinesh Awasti et al. (2009) have listed some entry barriers of psycho-social nature faced by the first-time entrepreneurs such as negative self-image, low confidence, lack of initiative, poor entrepreneurial education and training, lack of business-related information, and low social status to entrepreneurial persuits. Thus, human and financial base of $R \& D$ framework needed to support manufacturing is weak in India.

\subsection{Manufacturing and Growth Promise}

Economic theory and empirical evidences have established that efficiency and profitability of the manufacturing sector can be enhanced with greater application of R\&D inputs. Denison (1982) in his pioneering work, established that nearly two-third of America's growth during the early stage of development was attributed to advancements in knowledge (R\&D). Later, Lall (1983) and Raut (1985) found R\&D activities crucial for industrial innovations and competitiveness. Data presented in Table-3 put forth our argument with some force. The countries who have larger proportion of their GERD to GNP ratio, business R\&D to GERD ratio, business $R \& D$ to sales turnover ratio, 
maintained a bigger proportion of manufacturing sector in national output composition. It can further be seen from the table- 3 that more than fifty percent of R\&D investment is funded by the business sector in industrially developed countries. In India, it is only $30.40 \%$, while this ratio is more than $70 \%$ in case of Japan and $68 \%$ in Germany. Their enterprises spent more than $2 \%$ of their sales volumes on R\&D efforts. Whereas in India, it is mere $0.55 \%$, even less than the business $R \& D$ to advertising ratio. This indicates that innovative investment suffered and must have consequently reduced the competitive capabilities of industries in a fiercely competitive world (Singh, 2011). The apparent positive association as depicted in the following table is, however, subject to in-depth examination. But information provided in Table-3 drives home the point that manufacturing sector could be strengthened with better outcomes of commercial R\&D. Besides the level of $R \& D$ expenditure, tax incentives to manufacturing industries can influence generation of business innovations. Mani (2008) empirically found that tax incentives did not have any impact on R\&D except chemical industries and explained the lack of a significant relationship between $R \& D$ and tax foregone as a result of tax subsidy covering only a small part of R\&D undertaken by the few industries.

Table 3: GERD to GDP Ratio, Business R\&D to GERD Ratio, Business R\&D to Sales Ratio and Manufacturing to GDP Ratio in different countries

\begin{tabular}{|c|c|c|c|c|}
\hline Country & $\begin{array}{c}\text { GERD as } \\
\text { Ratio to GDP } \\
(\boldsymbol{\%})\end{array}$ & $\begin{array}{c}\text { Business R\&D } \\
\text { as ratio to } \\
\text { GERD }(\boldsymbol{\%})\end{array}$ & $\begin{array}{c}\text { R\&D as Ratio } \\
\text { to Sales } \\
\text { Turnover }(\boldsymbol{\%})\end{array}$ & $\begin{array}{c}\text { Manufacturin } \\
\text { g/ GDP Ratio } \\
(\boldsymbol{\%})\end{array}$ \\
\hline China & 1.42 & 72 & 2.4 & 34.5 \\
\hline Taiwan & 2.90 & 69 & 2.2 & 25.6 \\
\hline Germany & 2.82 & 68 & 2.3 & 20.92 \\
\hline South Korea & 3.23 & 70 & 1.75 & 31.00 \\
\hline Japan & 3.40 & 75 & 3.5 & 19.00 \\
\hline India & 0.88 & 30.40 & 0.55 & 15.00 \\
\hline
\end{tabular}

Source: Author's compilation from different internet sources (data of different years)

Table-4 very clearly indicates that pharmaceuticals, chemicals, auto-components and IT industries were investing in $R \& D$ as proportion of their sales volumes well above the national average of $0.55 \%$. They have realised a growth rate ranging between 9-12 $\%$ which is much higher than the growth rate of manufacturing sector. A closer examination of pharmaceuticals, auto-parts, chemicals and IT products has brought into focus certain common features. They are backed by frugal $R \& D$ innovations, voluminous and quickness in production, globally competitive prices and better 
organizational management. These success stories of Indian manufacturers can be applied to larger parts of manufacturing sector in spite of the fact that their production is capital and high skilled intensive. These firms are the role models in the manufacturing business and considered amongst the world leaders in 'frugal innovations and frugal manufacturing' (GoI, 2008). A number of small manufacturers, especially in auto-parts in unorganized sector, are also contributing to quality production. Hence, there is a strong case for undertaking capacity-building exercise for a large number of small scale and micro-enterprises that have low technology and R\&D intensity. These marginal business units termed as 'cultural and creative' industries employ indigenous knowledge and entrepreneurial skills at low level. As already stated, flow of innovations is set by a given social milieu. It may however be nurtured through appropriate support mechanism and policy interventions. An attempt to encourage R\&D investment in organizational knowledge, marketing strategies, entrepreneurial development and business education is a supply- augmenting measure. The re-engineering model of growth followed in SouthEast Asian economies is not suited, nor practically possible in modern India in the wake of TRIPS regime. What is important is the creation of an environment that allows entrepreneurs to freely search and identify opportunities in the vertically integrated global supply chains of various industries (Veeramani 2013). The emerging production system has growth implications in tasks such as low-end assembly activities, back-end engineering, and components production which require low amount of capital and skill, if linked with the networks.

Table 4: Growth Rate and R\&D Intensity in Select Industries (2008-10)

\begin{tabular}{|l|c|c|}
\hline Industry & $\begin{array}{c}\text { Annual Average Growth } \\
\text { Rate (\%) }\end{array}$ & $\begin{array}{c}\text { R\&D Expenditure as } \\
\text { \% of Sales Turnover } \\
\text { (R\&D Intensity) }\end{array}$ \\
\hline Drugs \& Pharmaceuticals & $9-12$ & 4.3 \\
\hline Information Technology (IT) & $9-11$ & 3.4 \\
\hline Chemicals & $10-12$ & 1.6 \\
\hline Auto Components & $9-12$ & 1.3 \\
\hline
\end{tabular}

Source: Author's compilation based on industry information retrieved from internet

\subsection{Concluding Observations}

Indian manufacturing sector has been growing at a sluggish rate of little over 8 $\%$ annually since the last two decades. The manufacturing-GDP ratio remained stagnant, 
while the global manufacturing system has undergone drastic changes. The comparative cost advantages in terms of scale of operations have been replaced by growing network of production value chains. In the new world of manufacturing, countries engage in production and trade by specializing at the level of distinct product lines and process within each industry and outsource the rest to regions/countries where it could be produced cheaper and more intensively. The paradigm shift has stressed on the capabilities to engineer products quickly, cheaper and at low costs as the critical sources of competitive advantage in the global production networks. Evidences revealed that India played a minor role in this high degree of fragmentation-based vertical specialization in production. India's growth pattern in the past had a bias in favour of relatively skill and capital intensive production. This was not in alignment with the country's true comparative advantage in unskilled labour intensive manufacturing. The growth trajectory of India's manufacturing sector requires to improve competitiveness in order to speed up pace and enlarge its size beyond $15 \%$ of GDP. In a global and liberal economic environment, R\&D activities are crucial for growth and competitiveness of manufacturing industries. Innovation-led growth is more stable and autonomous. Inhouse Innovations in goods and processes can be instrumental to boost efficiency, profitability and market share. Available statistics indicate that Gross Expenditure on $\mathrm{R} \& \mathrm{D}$ (GERD) to GDP ratio of $0.88 \%$ is quite low in relation to comparable countries like China, Korea, and Taiwan. Indian business units seem to be complacent to R\&D efforts as shown by poor business R\&D to GERD ratio, R\&D to sales ratio as compared to Japan, Germany, and South Korea known for their innovation- led manufacturing. This underlines the need to raise R\&D investment in the country in general and business enterprises in particular by way of more wide-spread tax incentive schemes, for instance, to meet the challenges of rapidly changing global production environment.

Indian pharmaceuticals, IT, chemicals and auto-parts industries have recently achieved massive growth supported by their R\&D efforts. They have emerged as leaders and role models in R\&D and manufacturing. The success model of these industries is replicable and feasible in the large array of Indian manufacturing industries including traditional and small scale industries which have much room for R\&D to strongly present their upgraded, diversified and exclusive products in the global market. India has no dearth of innovative ideas at the grass root level, yet the rate of conversion of these ideas into viable business is low due to lack of risk- taking ability, resources and patronage. There is vast untapped potential of young entrepreneurs who confront a lot of psycho-social barriers at the entry level. As innovations are policy-determined, promoting quality education to foster entrepreneurial values, risk-taking preparedness and business-linked skills may be long term supply-centric measures. The consequent 
increased participation in global production network is, therefore, key to the strategy to lead the manufacturing on the sustainable growth path.

\section{References}

Cohen, W.M. and Levin, R.C. (1989). Empirical Studies of Innovation and Market Structure. In R.C.Schmalense \& R.Willing (eds.) Handbook of Industrial Organization, 1059- 1107, Amsterdem, Elsevier.

Danison, E.F. (1982). Trends in American Economic Growth, 1929-82. Washington, D.C., Brookings Institution.

Desai,V. Ashok (1982). Technology Import Policy in the Sixties and Seventies: Changes and their Consequences, Memeo, NCAER and ICRIER, New Delhi.

Awasthi, D., Kashyap SP, \& Yagnik, J. (2009). Changing Sectoral Profile of Urban Economy and Implications for Urban Poor. In (eds.) India; Urban Poverty Report 2009, Oxford University Press, New Delhi.

GOI. (2008). R\&D Statistics, 2007-2008, Ministry of Science and Technology, Department of Science \& Technology, New Delhi.

GOI . (2008). Eleventh Five Year Plan, 2007-12, Oxford University Press, New Delhi.

GOI. (2011). Faster, Sustainable and More Inclusive Growth, An approach to the Twelfth Five Year Plan, Planning Commission, New Delhi.

Gupta, Poonam, Hasan, Rana \& Kumar, Utsav. (2010). What constraints India's manufacturing. In Barry Eichengreen, Poonam Gupta and Ranjan Kumar (eds.) Emerging Giants: China and India in the World Economy, New York: Oxford University Press, 307-39.

Indiresan, P.V. (2004). Rural Development and Technology Management: Vision 2020. In S.P. Gupta (ed.) Vision 2020, GOI, New Delhi, 573-651. 
32 | PRAGATI: Journal of Indian Economy, Volume 3, Issue 1

Kochchar, Kalpana, Kumar, Utsav, Rajan, Raghavan, Subramaniam, Arvind \& Tohalidis, Ioannis. (2006). India's pattern of development: What happened, what follows. Journal of Monetary Economics, 53(5), 981-1019.

Krueger, Anne O. (2010). India's Trade with the World: Retrospect and Prospect. In Sharkar Acharya and Rakesh Mohan (eds.), India's Economy. New Delhi: Oxford University Press, 399-429.

Lall, Sanjaya (1983). Determinants of R\&D in an LDC: The Indian engineering industry. Economic Letters, 379-83.

Lakhwinder, Singh (2001). Public policy and expenditure on R\&D in industry. Economic and Political Weekly, August 4, 2920-24.

Mani, Sunil. (1999). Industrial R\&D: What should governments do? Economic \& Political Weekly, Feb.27, 34-38.

Mani, Sunil. (2011). National manufacturing policy: Making India a powerhouse? Economic \& Political Weekly, xlvi (53).

Mani, Sunil. (2009). Is India becoming more innovative since 1991: Some disquieting features. Economic \& Political Weekly, xliv (46).

Mani, Sunil. (2008). Financing of industrial Innovations in India, how effective are tax incentives for R\&D. Working Paper Series No. 405, CDS, Thiruvanthapuram.

Nagraj, R. (2011). Industrial Performance, 1991-2008: A Review. In D. M. Nachare (eds.) India Development Repute 2011. New Delhi: Oxford University Press, 69-80.

Panagriya, Arvind. (2008). India: The Emerging Giant, New York: Oxford University Press.

Raut, L.K.(1985). R\&.D Behaviour of Indian Firms: A Stochastic Control Model. In Three Essays on Inter-temporal Economic Development. Unpublished PH.D. Dissertation. Yale University, New Haven, CT. 
Sankalpa, Bhattachargee and Debkumar, Chakrabarti. (2013). Financial Liberalisation, Financing Constraints and India's Manufacturing Sector. Economic and Political Weekly, Feb.9, 61-67.

Veeramani, C. (2013). The 'Miracle' still waiting to happen: Performance of India's Manufactured Exports in Comparison to China. In S.Mahendra Dev (eds.) India Development Report, 2012-2013, IGDRI, Oxford University Press, New Delhi,132-50.

Weiss, John. (2011). Economics of Industrial Development, London \& New York:Routledge.

Wesley, M. Cohen \& Levinthal, Daniel A. (1990). Absorptive capacity: A new perspective on learning and innovation. Administrative Science Quarterly, 35:1,128-52. 